\title{
Military genitourinary injuries: past, present, and future
}

\author{
Felicia L. Balzano, Steven J. Hudak \\ Brooke Army Medical Center, Fort Sam Houston, TX, USA \\ Contributions: (I) Conception and design: SJ Hudak; (II) Administrative support: FL Balzano; (III) Provision of study materials or patients: SJ Hudak; \\ (IV) Collection and assembly of data: All authors; (V) Data analysis and interpretation: All authors; (VI) Manuscript writing: All authors; (VII) Final \\ approval of manuscript: All authors. \\ Correspondence to: Steven J. Hudak, MD. Brooke Army Medical Center, MCHE-ZSS-U, 3551 Roger Brooke Drive, Fort Sam Houston, TX 78234, \\ USA. Email: steven.j.hudak2.mil@mail.mil.
}

\begin{abstract}
Genitourinary $(\mathrm{GU})$ injuries among military service members are as old as war itself. The frequency and clinical picture of GU injuries sustained in conflicts over the ages have evolved along with the constantly changing nature of combat. In this review, we discuss changing trends in the diagnosis and management of GU injuries over the past century and introduce areas of innovation which could impact the care of casualties who sustain GU trauma in the future.
\end{abstract}

Keywords: Genitourinary injury; military personnel; wartime

Submitted Dec 01, 2017. Accepted for publication Mar 30, 2018.

doi: 10.21037/tau.2018.04.05

View this article at: http://dx.doi.org/10.21037/tau.2018.04.05

\section{Introduction}

While genitourinary (GU) injuries have been sustained during combat throughout the ages, they have not received much attention in the recent scientific literature. This is likely due to the relatively nonlethal nature of GU injuries and their relatively low frequency when compared to injuries to other body regions and organ systems. However, GU injury is an important component of wartime morbidity and must be considered given the potentially devastating sexual, urinary, reproductive, and psychological sequela in the short and long term.

This article reviews important changes in the epidemiology, clinical course, and outcomes of battlefield GU injuries throughout the last two centuries. It also summarizes lessons learned from past conflicts to understand how trauma teams can better manage GU injuries in the future. These lessons can aid in the development of research protocols and treatment guidelines to ensure the best possible outcomes for victims who sustain $\mathrm{GU}$ injuries during future conflicts.

\section{The past}

\section{Pre-21 $1^{\text {st }}$ century conflicts}

Data on GU injuries sustained during late $19^{\text {th }}$ and early $20^{\text {th }}$ century conflicts is sparse; however there were two overarching trends worth noting. First, relative to other organ systems, GU injuries were uncommon. Second, renal and bladder injury predominated over external GU injuries (1). During the late $20^{\text {th }}$ century, body armor modifications as well as a shift in weapon use from predominantly high velocity rounds to explosive munitions likely resulted in shift from internal GU injuries (renal, bladder) to genital injuries becoming more predominant $(1,2)$.

During the Civil War, few data about abdominal GU injuries were published, likely due to the high lethality of penetrating abdominopelvic wounds during that era. Injuryrelated urinary extravasation that was unable to be diverted initially was uniformly fatal. Urethral injuries, when present, were survivable, but usually resulted in long term disability from urinary fistulae, indwelling catheters and/ 
or chronic infection. Perineal urethrostomy was frequently utilized, as was suprapubic cystostomy for urine drainage. Primitive catheter materials (i.e., metal or stiff gum) could cause erosion or stone formation in less than a week. Catheter displacement was common, thus requiring further instrumentation and risk for false passage formation upon replacement $(3,4)$.

As time and technology progressed, so did injury evaluation and management. During World War II, reports of GU injuries came from a variety of sources, typically from the hospital where injured patients received their definitive care. This challenged analysis of injury patterns and management, but some technical points are worthy of discussion. Bladder injuries were predominately intraperitoneal and were closed primarily when possible (5). In the case of a suspected urethral injury, catheter placement was attempted with simultaneous digital guidance per rectum to determine whether displacement of the catheter, gross prostatic injury, and/or or displaced fragments of the bony pelvis were evident. This somewhat primitive form of primary urethral realignment was attempted in all cases regardless of the location or severity of injury (5). In the case of prostatic displacement, the prostatic apex was sutured to the triangular ligament suprapubically and placed on traction (5). Large bore catheters ( 24 or $26 \mathrm{~F}$ ) were utilized with the hope that future stricture formation would be prevented.

Documentation of GU injuries during the Vietnam War was challenged by the more rapid local and regional casualty evacuation patterns utilized. Overarching trends included demonstration of the complex, multi-system nature of injuries associated with GU trauma. At one hospital, only $0.5 \%$ of men had isolated GU injuries (6). Casualty evacuation improved remarkably during the Vietnam War, with the transition from ground-based to airborne evacuation systems. Subsequently, the average time from injury to arrival at a field hospital for definitive care was 16 hours in World War II vs. 1 hour in the Vietnam War (7).

Genital trauma management during the Vietnam War began with an attempt at urethral catheter placement, often without radiographic or endoscopic staging for urethral injury (8). Urethral repair was always attempted at the time of injury and the catheter was placed on traction for 3 weeks (8). Subsequent data emerged suggesting that staged repairs of urethral injuries provided better long term outcomes with fewer complications (9).

During the Bosnian War, the majority of GU injuries were caused by improvised explosive device (IED) blasts, most of which were managed surgically. Nephrectomy, retroperitoneal hematoma evacuation and orchiectomy were the most common surgical procedures performed (2). Use of protective body armor and helmets during this conflict were the exception rather than the norm (2). During Operation Desert Storm, however, the decreased proportion of renal and ureteral injuries vs bladder and genital injuries was thought to be related to the increased utilization of Kevlar ${ }^{\circledR}$ body armor among U.S. service members $(10,11)$. This trend toward genital injuries would continue during $21^{\text {st }}$ century conflicts.

\section{$G U$ injury in operation Iraqi freedom/operation enduring freedom}

During U.S. involvement in Iraq and Afghanistan, a number of factors converged which ultimately resulted in the frequency of genital injuries increasing to a level never before reported in the history of war (12). The majority of injuries sustained during these conflicts were caused by ground-based explosive mechanisms and frequently resulted in a unique injury pattern known as dismounted complex blast injury (DCBI), defined as blast injury to a dismounted troop resulting in multiple extremity amputations, pelvic fractures, and extensive genital/perineal wounds (13). This complex injury pattern was not commonly reported in previous conflicts because of the high mortality of polytraumatic explosive injuries. Fortunately, a number of $21^{\text {st }}$ century advances in combat casualty care (rapid casualty evacuation, tourniquet application, advanced resuscitation techniques, multidisciplinary damage control surgery) improved the survival of complex blast injury which in previous conflicts were uniformly fatal (13). An unfortunate consequence of decreased mortality rates after complex blast injury was that an unprecedented number of U.S. SMs survived to face the challenges of recovery from catastrophic genital injuries which in prior conflicts were not survivable.

After the formal conclusion of OIF and OEF, Janak et al. published a comprehensive review of the Department of Defense Trauma Registry (DoDTR) for GU injuries sustained by U.S. SMs in Iraq and Afghanistan, representing the largest series of military GU injuries ever reported. Nearly 30,000 U.S. SMs had injury codes available for review in the DoDTR during the 12 years analyzed. Among them $1,462(5.3 \%)$ U.S. SMs sustained 1 or more GU injuries. All but 20 were male and 75 of the SMs died of their wounds. Among the 1,367 male survivors, $88.6 \%$ of injuries were sustained in battle, $74.1 \%$ were caused by 
an explosive mechanism, and 1,000 (73.2\%) had at least 1 injury to the external genitalia. This included 760 men with scrotal injuries, 451 with testicular injuries, 423 with penile injuries, and 125 with urethral injuries (12). Severe polytraumatic injury was common among the male survivors with $62.1 \%$ having an injury severity score (ISS) of 16 or higher. Injuries reflective of the complexity of DCBI were common, including colorectal injury in $21.7 \%$, pelvic fracture in $25.0 \%$, traumatic brain injury in $40.2 \%$, and lower extremity amputation(s) in $28.3 \%$ (12). Severe GU injury was identified in 502 men (36.7\%). Those with severe GU injury had higher rates of ISS $\geq 16$, colorectal injury, pelvic fracture, and lower extremity amputation, suggesting that the complexity of GU injury is a surrogate for overall injury severity (12).

The recently published reports on contemporary battlefield GU injury discussed above provide a robust account of the high frequency and severity of complex genital injuries observed in modern warfare. Unfortunately, no studies have comprehensively evaluated the long term outcomes following GU injury in this setting. However, prospective evaluation of the large cohort of men who sustained GU injury during OIF/OEF is underway and will hopefully provide much needed information on this topic (12).

\section{The present}

\section{Primary management of battlefield GU injury}

When observed in isolation, GU injuries are rarely lifethreatening. Thus, when a polytrauma patient (civilian or military) presents with concomitant GU injury, principles of damage control resuscitation and surgery must be followed. Bladder drainage is typically obtained during the primary trauma survey, via transurethral or suprapubic catheterization, depending on the nature of associated genital injuries. Appropriate abdominopelvic axial imaging is performed (when available), consistent with wellestablished trauma guidelines, including collecting system and retrograde cystographic phases, when indicated. As discussed previously, contemporary conflicts have seen lower rates of renal, ureteral, and bladder injuries compared to genital injuries. When present, injuries to the upper GU tract are managed in a manner consistent with clinical guidelines utilized in non-combat scenarios (14).

Battlefield genital injuries should be evaluated in the operating room and copiously irrigated as soon as possible, especially in the blast setting as contamination from dirt, metal fragments, and other debris will occur and can negatively impact wound healing. Any actively bleeding penile or testicular vessels should be carefully ligated and/or fulgurated, when necessary. Excessive debridement should be avoided at this stage given the unique and difficultto-replace nature of the genital structures. The wound is then carefully packed with moist gauze and placed under compressive undergarments while the patient is further resuscitated.

Upon secondary surgical evaluation, thorough genital injury staging must be completed with urologist involvement, when available (15). For males, this includes examining the entire extent of the urethra (directly or endoscopically), corporal bodies, bilateral testicles with associated spermatic cords, and the surrounding genital skin/soft tissue. In females, thorough pelvic examination is necessary to evaluate for vulvovaginal injuries. If injury severity precludes adequate examination of an awake patient, examination under anesthesia is necessary to fully stage lower GU and reproductive injuries. Ideal exposure of these structures is obtained with lithotomy position if concomitant pelvic and orthopedic injuries allow for such positioning. Vaginal, urethral, and corporal lacerations should be irrigated and approximated, if possible. Simple testicular lacerations should be closed primarily after debridement of any necrotic or contaminated tubules. Larger defects in the tunica albuginea can be closed with a graft of tunica vaginalis. Orchiectomy may be appropriate for unilateral injuries determined to be non-salvageable. For bilateral injuries (or injury to a solitary testicle), every effort should be made to preserve even a small portion of a testicle, which may be adequate for androgen production and thus possibly prevent the need for long term testosterone replacement.

After each of the deep genital structures has been staged, the skin and soft tissue must be examined for viability and quantity. For a small amount of tissue loss, these areas should be closed in multiple layers over a surgical drain or left to heal by secondary intention. In the instance of a large amount of skin loss, skin grafting should not be attempted in the acute setting as blast-related injury and wound contamination can impair graft take (15). Vacuumassisted wound dressings are most appropriate for the initial management of extensive genital skin loss.

During the days-to-weeks after the initial polytraumatic insult, the interval of wound dressing changes will depend on the severity of GU injury as well as concomitant injuries 
to other body systems. Most patients with complex blast injury will return to the operating room on a daily or everyother-daily basis for examination under anesthesia, dressing change, and further debridement, as necessary. During this time period, more definitive management of other concomitant injuries will be managed as needed. During each return trip to the operating room, genital tissue should be thoroughly evaluated for viability and necrotic tissue should be carefully debrided. Provided urinary drainage is adequate and infection is prevented, temporization of genital reconstruction can be indefinite. However, definitive genital reconstruction can ensue once the patient's overall condition has stabilized, tissue contamination/colonization has been controlled, and granulation tissue has formed.

\section{Long term management of external genital injury}

In the weeks and months that follow complex GU injury, a large number of patients may suffer from long term, quality of life-limiting complications such as sexual dysfunction with or without associated hypogonadism (16), urinary symptoms, and reproductive difficulties. Each of these must be thoroughly evaluated and treated using a diverse array of surgical, medical, and psychological approaches.

Reconstructive surgery after complex GU injury aims at salvaging remaining $\mathrm{GU}$ tissue while restoring genital structures to be as functional and cosmetically similar to uninjured structures as possible. When deep structures (i.e., corpora cavernosa, testes, etc.) are preserved, split thickness skin grafts are preferred for wound coverage and initial reconstruction. For penile reconstruction, thicker skin grafts are preferred (i.e., 0.016 inch) and graft take is improved by manually pie crusting or meshing the graft in a 1:1 nonexpanded manner. Circumferential penile skin grafts are placed with the seam on the ventrum of the penile shaft, thus approximating a normal penile raphe. When scrotal skin has been lost, the testes are secured to one another in the midline to prevent torsion and to provide a scaffold on to which splitthickness skin grafts are placed for neo-scrotal reconstruction. Scrotal reconstruction is best performed using a thinner graft (i.e., 0.012 inch) with 1:1.5 pie crusting to optimize graft take. This also allows the interstices of the meshed graft to heal in a manner that has a similar cosmetic appearance to the native scrotal rugae (17).

When corporal, urethral, and/or testicular tissues are lost, more complex surgical maneuvers, such as pedicled or free flaps may be required. Given the surgical complexity of genital reconstruction, temporization may be required until the patient has appropriately recovered and requisite surgical expertise is available. In such cases, the injured urethra can be matured to the overlying skin as distal as possible along the genital axis, thus facilitating future urethral reconstruction. When partial corporal loss has occurred, remaining corporal tissue should be grafted in a phallic shape, as even a traumatically foreshortened penis can retain an appropriate male habitus, allow for voiding from the standing position, and allow for erogenous sensation once the primary wounds are fully healed.

Far fewer options are available in the case of complete phallic loss. Either radial artery forearm free flap (18) or anterolateral thigh flap (19) are appropriate for phallic reconstruction, depending on what concomitant extremity injury(-ies) may be present. Flap-based genital reconstruction is commonly performed for gender confirmation among the transgender population $(18,20)$ with good results. However, patients who have sustained polytraumatic blast injuries to the upper and/or lower extremities may not be candidates for such complex flapbased genital reconstructive procedures. Additionally, long term data on flap-based phalloplasty among complex blast injury patients is limited (18).

Sexual dysfunction among polytrauma patients is usually multifactorial and must be treated as such. There are the physical aspects of damaged GU structures as well as medical and psychological factors. The extent of physical damage depends on the severity of initial injury, temporizing procedures required, and reconstructive surgeries performed. Both vascular and neurologic injuries to the GU structures may have been sustained. Additionally, medications that are utilized to treat comorbid psychiatric conditions such as depression or anxiety (i.e., benzodiazepines, narcotics and anti-depressants) can all cause or exacerbate sexual dysfunction (21). Fortunately, injured service members are largely young and respond well to first line erectile dysfunction medications, such as sildenafil, vardenafil and tadalafil. Non-responders should be offered intracavernous injections, intraurethral suppositories or penile prosthesis, as needed.

Hypogonadism (common among polytrauma patients) can exacerbate ED while its treatment can facilitate rehabilitation of both sexual and physical function (22). Patients who sustain bilateral testicular loss should begin testosterone replacement therapy as soon as possible (typically after transfer out of the intensive care unit). Men with pelvic blast injury and preserved testicular tissue should be screened and followed for hypogonadism. Many animal 
based studies and human investigations have confirmed that serum testosterone levels decrease to almost castrate immediately following complex polytrauma with or without testicular injury (23). For those who remain hypogonadal after recovering from the critical injury period, testosterone replacement may be helpful for the restoration of sexual and physical function. However, long term testosterone replacement therapy can suppress the hypothalamicpituitary axis and inhibit sperm production (24). Therefore, a discussion about long term fertility plans is necessary prior to initiating testosterone replacement therapy in male polytrauma patients.

\section{The future: innovations in battlefield GU injury care}

\section{Pelvic personal protective equipment (PPE)}

PPE has evolved continuously during combat in recorded history. In the Vietnam and Bosnian wars, body armor was not commonly worn by combat troops, and thus renal and ureteral injuries were more frequent when compared to the 1991 Gulf War when Kevlar ${ }^{\text {TM }}$ body armor became ubiquitous among U.S. service members (10).

The dramatic increase in genital injuries observed during OIF/OEF led to the rapid development and distribution of pelvic PPE among U.S. service members aimed at preventing and/or mitigating the uniquely devastating effects of ground based blasts on the perineal and genital structures (12). Currently implemented pelvic PPE among U.S. forces include an undergarment which can limit dirt and debris penetration of the perineal and genital soft tissues in addition to a Kevlar ${ }^{\mathrm{TM}}$ over-garment which protects the wearer from high velocity penetrating injury. An early evaluation of pelvic PPE revealed a 31\% absolute reduction in the rate of GU injury when pelvic PPE was worn by dismounted SMs who sustained lower extremity amputation(s) from blast injury, when compared to a similar group of blast-injured SMs not wearing pelvic PPE (25). Unfortunately, the added protection provided by pelvic PPE comes at the potential cost of comfort, mobility, and weight (26). Therefore, ongoing development of pelvic PPE should consider the unique balance between level of protection and ease of use specific to the $\mathrm{GU}$ region.

\section{Multidisciplinary care}

The immediate and long term care of patients who sustain complex polytrauma is best approached in a collaborative multi-disciplinary fashion, especially when GU injury is present. Genital injury can be a sensitive topic for patients and may be difficult for medical providers to discuss; however, it must not be avoided or ignored. One group of battlefield GU trauma patients surveyed stated that they would like clinical staff to be more open in discussing their GU injuries (27). As the severity of injury increases, the importance of open, honest discussion about injuries and how they will affect future sexual, urinary, and reproductive functions and subsequent quality of life for the patient and his/her intimate partner(s) increases proportionally.

Sexual health and penile rehabilitation not only provides psychological benefit to service members, but the increased blood flow of periodic erections can promote healing of erectile structures. Such erections may also prevent penile shortening, fibrosis and progressive erectile dysfunction. Because of this, treatment of patients with PDE-5 inhibitors should be started as soon as possible. It is imperative that sexual health be regarded with similar importance to other activities of daily living, particularly in young patients.

Physical rehabilitation is another important component of the multi-disciplinary approach that must be utilized when treating patients with complex GU injuries. Lower extremity injuries can impact sexual positioning in the same way they can alter the way an individual stands, walks or runs. It is therefore imperative that physical therapists discuss the aspects of sexual positioning with all polytrauma patients requiring extensive physical therapy, even in patients without genital injuries. Upper extremity injury can also affect sexual function for both the patient and their partner. However, discussing the physical aspects of masturbation and other intimate upper extremity functions may be unfamiliar or uncomfortable for some physical and occupational therapists. Fortunately, a recently published handbook provides a practical guide for rehabilitation specialists with limited experience addressing sexual health among polytrauma patients (28).

The large number of male service members who sustained genital injuries during OIF/OEF have given insight to the psychological impact complex GU trauma can have. Trauma team members should address the severity of injury and expected functional prognosis early after the injury. Repeat visits and discussions are often necessary to ensure full and complete understanding by the patient and his/her intimate partner(s). There is limited data which suggests that patients prefer clinical and prognostic information be delivered by the appropriate medical or surgical specialist (27). Patients should also be screened for 
post-traumatic stress disorder (PTSD) given its correlation with sexual dysfunction, even when GU injury is not present (29). Early involvement of a clinical psychologist well versed in sexual medicine may be helpful for long term psychological rehabilitation. This allows for clinical relationships to be formed early on that can be continued throughout the rehabilitation process.

\section{Fertility preservation/restoration}

Reproductive function after GU injury is another important area where future improvements are needed. The impact of a potentially sterilizing GU injury may be amplified among young service members, especially those who are unmarried and/or have the desire to have biological children. Postinjury gamete salvage has been efficacious for a small number of male service members who sustained genital trauma during OIF/OEF. Sperm harvested from either the seminal vesicle (30) or the remnant vas deferens (27) have been successfully salvaged, cryopreserved, and utilized for subsequent successful in vitro fertilization in men who sustained injuries which would have rendered them otherwise infertile. However, the financial, ethical, and logistical challenges of these approaches have limited their widespread use in both military and civilian GU trauma settings.

Pre-deployment gamete (sperm and ovum) cryopreservation is a promising option for service members deployed to environments with a high risk for complex GU injury. There is a pilot program currently evaluating the feasibility of gamete preservation among U.S. service members (12), but the efficacy and scalability of this program remains uncertain. If successfully implemented, such a program could allow male and female service members to maintain reproductive capabilities should complex GU or reproductive injury occur.

\section{Penile transplantation}

Reconstructive transplantation offers the potential to replace "like-with-like," thus restoring penile form and function. Recent successful penile allotransplantation among two non-blast injured men $(31,32)$ offers great promise for men who sustain penile loss of any etiology. However, given the local, systemic, and psychological complexities of polytraumatic genital blast injury (33), the future of penile transplantation among men who sustained combat related genital loss is uncertain. The unique aspects of blast injury must be carefully considered should penile transplant teams offer penile transplantation to U.S. service members who sustained complex polytraumatic genital injury, ideally in the form of a clinical trial.

\section{Conclusions}

GU injuries on the battlefield have been present throughout the ages and ongoing management of $\mathrm{GU}$ injuries continues to be a challenging task. Although many improvements have been made to protective equipment and multidisciplinary care, there is still substantial room for improvements in GU injury prevention, initial care, and long term management. War provides a unique set of problems for the urologist and as the face of war changes, GU injury care must adapt so challenges can be faced and outcomes can be improved.

\section{Acknowledgements}

None.

\section{Footnote}

Conflicts of Interest: The authors have no conflicts of interest to declare.

Disclaimer: The view(s) expressed herein are those of the author and do not reflect the official policy or position of Brooke Army Medical Center, the U.S. Army Medical Department, the U.S. Army Office of the Surgeon General, the Department of the Army and Department of Defense or the U.S. Government.

\section{References}

1. Hudak SJ, Morey AF, Rozanski TA, et al. Battlefield urogenital injuries: changing patterns during the past century. Urology 2005;65:1041-6.

2. Zalihić D, Zalihic A. Comparison of the results of surgical and non-surgical treatment of combat urogenital injuries in Bosnia War 1992-1995. Coll Antropol 2011;35:227-33.

3. Herr HW. Urological injuries in the Civil War. J Urol 2004;172:1800-4.

4. Herr HW, McAninch JW. Urethral Injuries in the Civil War. J Urol 2005;173:1090-3.

5. Clarke BG, Leadbetter WF. Management of wounds and injuries of genito-urinary tract: a review of reported experience in World War II. J Urol 1952;67:719-39. 
6. Ochsner TG, Busch FM, Clarke BG. Urogenital wounds in Vietnam. J Urol 1969;101:224-5.

7. Busch FM, Chenault OW Jr, Zinner NR, et al. Urological aspects of Vietnam War injuries. J Urol 1967;97:763-5.

8. Rohner TJ Jr, Blanchard TW. Management of urethral injuries in war casualties. Mil Med 1970;135:748-51.

9. Salvatierra O Jr, Rigdon WO, Norris DM, et al. Vietnam experience with 252 urological war injuries. J Urol 1969;101:615-20.

10. Thompson IM, Flaherty SF, Morey AF. Battlefield urologic injuries: the Gulf War experience. J Am Coll Surg 1998;187:139-41.

11. Abu-Zidan FM, Al-Tawheed A, Ali YM. Urologic injuries in the Gulf War. Int Urol Nephrol 1999;31:577-83.

12. Janak JC, Orman JA, Soderdahl DW, et al. Epidemiology of Genitourinary Injuries among Male U.S. Service Members Deployed to Iraq and Afghanistan: Early Findings from the Trauma Outcomes and Urogenital Health (TOUGH) Project. J Urol 2017;197:414-9.

13. Cannon JW, Hofmann LJ, Glasgow SC, et al. Dismounted Complex Blast Injuries: A Comprehensive Review of the Modern Combat Experience. J Am Coll Surg 2016;223:652-64 e8.

14. Morey AF, Brandes S, Dugi DD 3rd, et al. Urotrauma: AUA guideline. J Urol 2014;192:327-35.

15. Williams M, Jezior J. Management of combat-related urological trauma in the modern era. Nat Rev Urol 2013;10:504-12.

16. Wilcox SL, Redmond S, Hassan AM. Sexual functioning in military personnel: preliminary estimates and predictors. J Sex Med 2014;11:2537-45.

17. Hudak S. Complex Genital Trauma: Lessons Learned from Operation Iraqi Freedom and Operation Enduring Freedom. Current Trauma Reports 2017;3:1-7.

18. Garaffa G, Ralph DJ. Free Flap Phalloplasty For Female To Male Gender Dysphoria. J Sex Med 2016;13:1942-7.

19. Gurjala AN, Nazerali RS, Salim A, et al. World's First Baby Born Through Natural Insemination by Father With Total Phalloplasty Reconstruction. Ann Plast Surg 2016;76 Suppl 3:S179-83.

20. Neuville P, Morel-Journel N, Maucourt-Boulch D, et al. Surgical Outcomes of Erectile Implants After Phalloplasty: Retrospective Analysis of 95 Procedures. J Sex Med 2016;13:1758-64.

21. Cohen SD. The Challenge of Erectile Dysfunction Management in the Young Man. Curr Urol Rep 2015;16:84.
22. Woods DR, Phillip R, Quinton R. Managing endocrine dysfunction following blast injury to the male external genitalia. J R Army Med Corps 2013;159 Suppl 1:145-8.

23. Williams M, Rosner I, Chen Y, et al. Testosterone recovery after polytrauma and scrotal injury in patients from Operation Enduring Freedom and Operation Iraqi Freedom. J Urol 2015;193:618-22.

24. Crosnoe LE, Grober E, Ohl D, et al. Exogenous testosterone: a preventable cause of male infertility. Transl Androl Urol 2013;2:106-13.

25. Oh JS, Do NV, Clouser M, et al. Effectiveness of the combat pelvic protection system in the prevention of genital and urinary tract injuries: An observational study. J Trauma Acute Care Surg 2015;79:S193-6.

26. Myers M. Army Designs New Harness to Protect your Groin From Blast Debris. Army Times. 2016. Available online: https://www.armytimes.com/news/your-army/2016/11/16/ army-designs-new-harness-to-protect-your-groin-fromblast-debris/. Accessed November 16, 2016.

27. Lucas PA, Page PR, Phillip RD, et al. The impact of genital trauma on wounded servicemen: qualitative study. Injury 2014;45:825-9.

28. Ellis K, Dennison C. Sex and Intimacy for Wounded Veterans: A Guide to Embracing Change. Los Angeles, California: The Sager Group; 2014.

29. Breyer BN, Fang SC, Seal KH, et al. Sexual Health in Male and Female Iraq and Afghanistan U. S. War Veterans With and Without PTSD: Findings From the VALOR Cohort. J Trauma Stress 2016;29:229-36.

30. Healy MW, Yauger BJ, James AN, et al. Seminal vesicle sperm aspiration from wounded warriors. Fertil Steril 2016;106:579-83.

31. Bateman C. World's first successful penis transplant at Tygerberg Hospital. S Afr Med J 2015;105:251-2.

32. Cetrulo CL Jr, Li K, Salinas HM, et al. Penis Transplantation: First US Experience. Ann Surg 2018;267:983-8.

33. Hudak S, Janak J, Orman J, et al. PD63-01 Severe Penile Injuries Sustained During Operations Iraqi And Enduring Freedom: Evaluating The Tough Cohort For Penile Transplantation. J Urol 2017;197:e1254.

Cite this article as: Balzano FL, Hudak SJ. Military genitourinary injuries: past, present, and future. Transl Androl Urol 2018;7(4):646-652. doi: 10.21037/tau.2018.04.05 